\title{
Left ventricular hypertrophy with right ventricular outflow obstruction
}

\author{
T. Dellocchio, A. Dolara, L. Salvatore, and R. Vergassola \\ From the Department of Cardiology, Arcispedale of S. M. Nuova, Firenze, \\ Clinica Chirurgica, Università di Firenze, Italy
}

A 21-year-old man, presenting electrocardiographic and angiographic evidence of left ventricular hypertrophy, showed at catheterization isolated obstruction of the outflow tract of the right ventricle.

Pressure gradients in the right ventricle of patients with hypertrophic cardiomyopathy are usually associated with outflow obstruction of the left ventricle (Braunwald et al., 1964; Mason, Braunwald, and Ross, 1965). Occasionally patients with pure right-sided obstruction have been reported (Braunwald et al., 1964; Taylor, Bernstein, and Jose, 1964; Mason et al., 1965; Falcone, Moore, and Lambert, 1967; Morrow, Fisher, and Fogarty, 1969). In these cases involvement of the right side of the heart corresponds to an electrocardiographic picture of right ventricular hypertrophy. It is exceptional to find in these patients an electrocardiographic pat- tern of left ventricular hypertrophy (Taylor et al., 1964). The following case is therefore considered worthy of reading.

\section{Case report}

A strong, apparently healthy, young man of 21 , was admitted to our hospital on 6 February 1970 for evaluation of a heart murmur.

No member of the family was affected by heart disease. He had scarlet fever and diphtheria during childhood, but no cardiac abnormality was discovered till he was 20 years of age. At that time he was found to be affected by cardiomyopathy and since then he had noted moderate dyspnoea after unusual effort.

\section{FIG. I Electrocardiogram.}
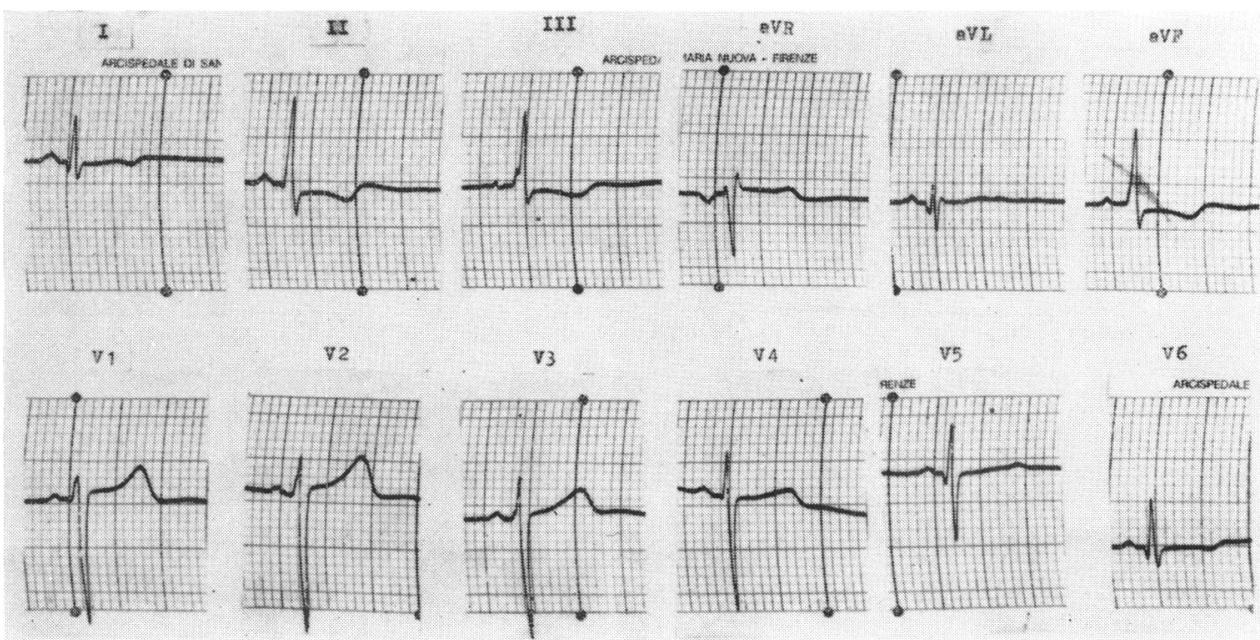

v5

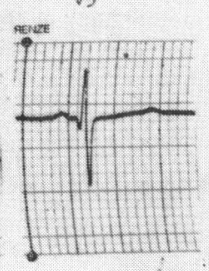




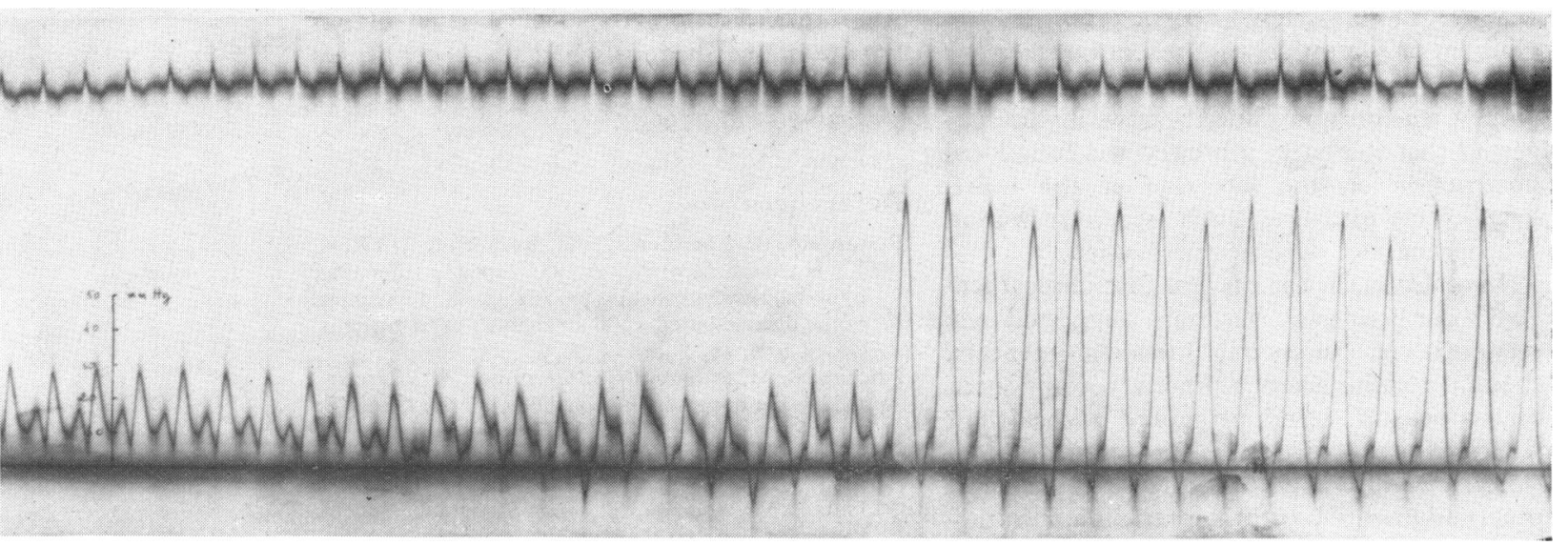

FIG. 2 Record of pressures obtained during withdrawal of the catheter from the pulmonary artery to the right ventricular inflow tract through an intermediate chamber (middle of record).

Abnormal physical findings were limited to the heart: auscultation revealed a widely split second sound with a diminished pulmonary component and an ejection murmur, grade $3 / 6$, in the second left intercostal space at the sternal edge. Administration of isoprenaline augmented the intensity of the murmur, while propranolol abolished this effect.

Electrocardiogram showed left ventricular hypertrophy (Fig. I). Chest $x$-ray revealed moderate enlargement of cardiac shadow.

Right and left heart catheterization (Table) showed a slight pressure gradient between the inflow and the outflow tract of the right ventricle under basal conditions when the catheter was withdrawn from the pulmonary artery to the right atrium. Isoprenaline administration induced a conspicuous increase of systolic pressure in the body of the right ventricle (Fig. 2). No obstruction to left ventricular outflow was demonstrated either under basal conditions or after infusion of isoprenaline. Angiography revealed an obvious

TABLE Cardiac catheterization of data

\begin{tabular}{|c|c|c|}
\hline & \multirow{2}{*}{$\begin{array}{l}\begin{array}{l}\text { Basal } \\
\text { condition }\end{array} \\
\begin{array}{l}\text { Pressure } \\
(m m H g)\end{array}\end{array}$} & \multirow{2}{*}{$\begin{array}{l}\begin{array}{l}\text { During } \\
\text { isoprenaline } \\
\text { administration }\end{array} \\
\begin{array}{l}\text { Pressure } \\
(\text { mmHg })\end{array}\end{array}$} \\
\hline & & \\
\hline Right atrium (mean) & 2 & - \\
\hline Right ventricular inflow & $35 / 4 / 6$ & $75 / 8$ \\
\hline Right ventricular outflow & $24 / 2 / 8$ & $24 /-8 ;-I$ \\
\hline Right ventricular apex & - & - \\
\hline Pulmonary artery & $24 / 12$ & $27 / 7$ \\
\hline Pulmonary artery wedge & & \\
\hline $\begin{array}{l}\text { (mean) } \\
\text { Aorta }\end{array}$ & $\begin{array}{l}15 \\
140 / 80\end{array}$ & $\overline{\mathrm{x} 57 / 72}$ \\
\hline Left ventricle & $140 / 12 / 30$ & $156 / 0$ \\
\hline
\end{tabular}

increase of thickness of the left ventricular walls (Fig. 3).

\section{Discussion}

In 1964, Taylor et al. reported the case of a patient, aged 53, in whom an ejection systolic murmur was equally heard in the aortic area, left sternal edge, and the apex; moderate enlargement of the heart on $x$-ray and considerable left ventricular hypertrophy at electrocardiographic examination led to the diagnosis of functional subaortic stenosis. At catheterization only a small systolic pressure gradient, up to $17 \mathrm{mmHg}$, was found between the left ventricle and brachial artery in beats following a long post-ectopic pause. Con-

FIG. 3 Left ventricular angiography in the left oblique anterior view.

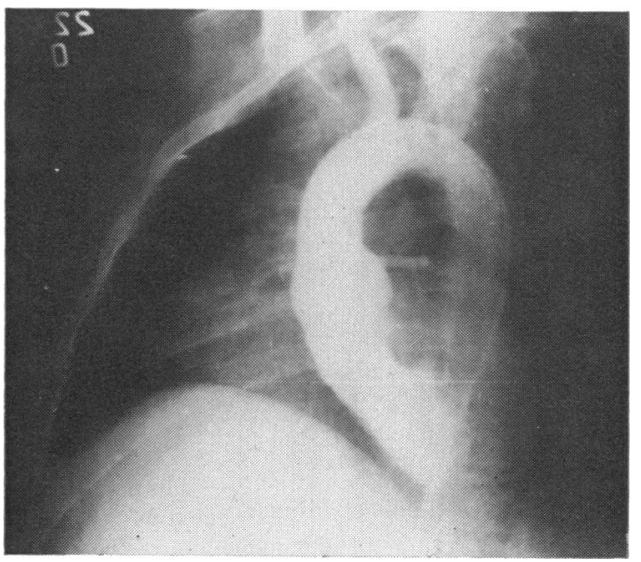


versely, in the right ventricle a pressure gradient of $47 \mathrm{mmHg}$ was present between the apex and the body of the chamber. Since the patient was on quinidine therapy, it was suggested that the latter inhibited the functional obstruction on the left side of the heart. Provocative measures, such as administration of isoprenaline, were not performed.

In addition, in the present case clinical and electrocardiographic findings suggested the diagnosis of functional subaortic stenosis, though a diminished pulmonary component of the second sound prompted a coexistent right-sided obstruction. At catheterization an isolated right ventricular pressure gradient, much augmented with isoprenaline administration, was in evidence (Fig. 2). Accordingly both the case of Taylor et al. and the one reported here underline the need to explore right ventricular cavities with accuracy, even in patients with hypertrophic cardiomyopathy and electrocardiographic evidence of pure left ventricular hypertrophy (Fig. I and 3).

While in the case of Taylor et al. a 'cavity obliteration' of the apex of the right ventricle with resulting entrapment of the catheter tip within or between the trabeculae of an hypertrophied ventricle was probably present (Lockhart et al., 1966), in our case catheterization findings suggested the presence of a true, low infundibular stenosis (Fig. 2). If there were an indication for surgical relief of obstruction, the diagnosis had to be confirmed by selective right ventricular angiography (Morrow et al., 1969).

\section{References}

Braunwald, E., Lambrew, C. T., Rockoff, S. D., Ross, J., Jr., and Morrow, A. G. (I964). Idiopathic hypertrophic subaortic stenosis: I. A description of the disease based upon an analysis of 64 patients. Circulation, 30, Suppl. 4, p. 3.

Falcone, D. M., Moore, D., and Lambert, E. C. (1967). Idiopathic hypertrophic cardiomyopathy involving the right ventricle. American fournal of Cardiologyo 19, 735 .

Lockhart, A., Charpentier, A., Bourdarias, J. P., Ben Ismail, M., Ourbak, P., and Scebat, L. (1966). Right ventricular involvement in obstructive cardiomyopathies: haemodynamic studies in 13 cases. British Heart fournal, 28, I22.

Mason, D. T., Braunwald, E., and Ross, J., Jr. (1965). Haemodynamic alterations induced by isoprenaline in patients with obstruction to right ventricular outflow. British Heart fournal, 27, 884.

Morrow, A. G., Fisher, R. D., and Fogarty, T. J. (I969). Isolated hypertrophic obstruction to right ventricular outflow. American Heart fournal, 77, 814.

Taylor, R. R., Bernstein, J., and Jose, A. D. (1964). Obstructive phenomena in ventricular hypertrophy. British Heart Fournal, 26, 193.

Requests for reprints to Dr. Alberto Dolara, Electrocardiological Service, Arcispedale of S. M. Nuova, Florence, Italy. 